Editorial

\title{
Impact of COVID-19 on Health Infrastructure and Wellness
}

\author{
Parmod K. Bithal ${ }^{1}$ Girija P. Rath ${ }^{2}$ \\ ${ }^{1}$ Department of Neuroanaesthesiology and Critical Care, All India \\ Institute of Medical Sciences, New Delhi, India (Retired) \\ 2Department of Neuroanaesthesiology and Critical Care, All India \\ Institute of Medical Sciences, New Delhi, India \\ J Neuroanaesthesiol Crit Care:2020;7:115-117
}

The coronavirus (COVID-19) pandemic has ravaged India with more than 8.14 million patients having contracted it and nearly 122,000 fatalities being recorded at the time of penning this editorial. Although pandemics, by their very nature, have a global impact, the effects on population vary disproportionately, according to the prevailing socioeconomic conditions. ${ }^{1}$ Countries that cannot guarantee social protection and equitable access to health care to their most vulnerable citizens run the risk of an extended and more severe pandemic. $^{2}$

\section{Infrastructure}

The COVID-19 pandemic has exposed several underlying issues with health care systems across the globe. While only a small fraction of COVID-19 patients require intensive care unit (ICU) care and mechanical ventilation, the sheer numbers involved mean that the availability of these life-saving resources becomes a pressing concern. Health care systems of low-and middle-income countries (LMICs), which are typically overburdened even in normal times due to issues with capacity, resources, and accessibility, have been seen to approach breaking point during this pandemic, which leads to a compromise in quality of care provided and associated worse outcomes. ${ }^{3}$ Older patients have been observed to have significantly poorer outcomes during this pandemic, and it is a matter of grave concern that $69 \%$ of the global population aged 60 years and above live in these LMICs. ${ }^{4}$

Anticipation and development of a robust health care system is the key to preparing for such scenarios. Unfortunately, in most LMICs such as India, health care planning does not seem to have accounted for the potential of encountering events of this magnitude. As per the World Health Organization (WHO, 2011), India has only 0.7 beds per 1000 population compared with the global average of 2.7 beds per
1000 people. Currently, the ratio has not improved much and, in fact, has reduced further with an average of 0.55 beds per 1000 population. ${ }^{5}$ This ratio also varies by states, and one of the worst-hit states of the country, Maharashtra, has a total of just over 51,000 public hospital beds, which would be woefully inadequate even in a nonpandemic scenario. To resolve this problem, there has been an increased interest in the rapid creation of makeshift new hospitals according to need. In India, several ingenious solutions have been attempted to compensate for the paucity of quarantine hubs and hospitals during this outbreak. ${ }^{6}$

Confirmed cases have been cohorted in open ICUs with adequate ventilation. Opening field hospitals in large public spaces (e.g., stadiums, hotels), as was practiced in some places, allows for triage and management of stable patients and decongestion of tertiary care ICUs, which then can be utilized for more critical patients. Stable patients with COVID-19, instead of being quarantined in hospitals, may be quarantined in specially designated places such as a hotel, a policy followed in India. Train bogies have been converted into patient beds to manage patients with mild disease. The emergence of telemedicine has allowed patients with mild symptoms to be sent home with instructions to safely isolate themselves (home quarantine) and be allowed to be monitored remotely. The provision of oxygen saturation monitors (pulse oximetry) and explaining the significance of its readings to patients and relatives have helped create home-based care and reduced the load on hospitals. Operating rooms and clinics may be converted to makeshift ICUs to cope with the increasing load of critically ill patients. To achieve this goal, non-emergent services such as elective surgeries may be reduced. The outpatient departments and clinics may temporarily be replaced with telemedicine facilities. All such measures help reducing costs, permitting capacity expansion, as well as improving the quality of care.

\author{
Address for correspondence \\ Girija Prasad Rath, MD, Department \\ of Neuroanaesthesiology and Critical \\ Care, All India Institute of Medical \\ Sciences, New Delhi 110029, India \\ (e-mail: girijarath.aiims@gmail.com).
}

DOI https://doi.org/ 10.1055/s-0040-1721520 ISSN 2348-0548.

\footnotetext{
(C) 2020. Indian Society of Neuroanaesthesiology and Critical Care. This is an open access article published by Thieme under the terms of the Creative Commons Attribution-NonDerivative-NonCommercial-License, permitting copying and reproduction so long as the original work is given appropriate credit. Contents may not be used for commercial purposes, or adapted, remixed, transformed or built upon. (https://creativecommons.org/licenses/by-nc-nd/4.0/). Thieme Medical and Scientific Publishers Pvt. Ltd., A-12, 2nd Floor, Sector 2, Noida-201301 UP, India
} 


\section{Monitoring Equipment}

As opposed to some other healthcare systems, a substantial portion of costs associated with critical care in developing nations is dedicated to the funding of staffing and acquisition of fixed equipment rather than the cost of medications or investigations. ${ }^{7}$ A potential solution to such costs could be the emergence of wearable healthcare technology, leading to physiological monitoring becoming more cost-effective. Such technology may reduce the need for more expensive equipment to monitor physiological parameters and improve the quality of care when used in conjunction with newer technologies such as machine learning and artificial intelligence (AI). ${ }^{8}$ Indeed, wearable devices have been seen to correlate well with conventional modalities such as electrocardiograms (ECG). ${ }^{9}$ Algorithms using machine learning software can be developed to process the vast amounts of data pertaining to the patient physiology. They may lead to the development of prediction models and assistance in making clinical decisions, as has been seen in managing conditions such as sepsis. ${ }^{10-12}$

Point of care diagnostic and imaging devices are also gaining popularity in the critical care setting due to their increasing availability and affordability. Newer devices such as portable ultrasound probes that can connect to tablets and mobile phones have the potential to make bedside ultrasound imaging accessible at all levels of healthcare and aid in providing quality care even in resource-limited settings. AI may also help in this setting, with machine learning-based image interpretation providing guidance and improving decision making in various clinical scenarios, even in the hands of relatively inexperienced providers. ${ }^{13}$

\section{Treatment Strategies}

Transport ventilators and anesthesia machines have been deployed as alternative means to provide invasive ventilation in the absence of conventional ICU ventilators. Portable oxygen concentrators have been used in field hospitals rather than oxygen tanks or cylinders due to their mobility. Prone positioning has emerged as a low-risk, low-cost measure that has helped patients with COVID-19 pneumonia in reducing oxygen requirements, decreased the need for ventilatory support, and reduced ICU care. ${ }^{13}$ The incorporation of high-efficiency particulate air (HEPA) filters in the expiratory limb of the circuit may help reduce aerosol generation if the ventilator does not have a closed circuit. Other innovative approaches include division of the ventilatory support to several similar patients simultaneously, with the use of T-tubes and pressure-cycled ventilation. ${ }^{14,15}$ Meanwhile, various automated bag devices have been developed, which are known as emergency use resuscitator systems (EURS). In India, Christian Medical College at Vellore has developed a noninvasive ventilator in which oxygen is delivered under high pressure to the patient by a ventilator using a snugly fitting face mask or helmet interface. ${ }^{16}$ Other similar approaches to save ICU resources may include the use of enteral vasopressors, like midodrine for hypotensive patients, instead of intravenous medications. ${ }^{17}$
Focusing on the development of makeshift infrastructure for the duration of the pandemic alone seems to be a short-sighted approach. Governments will also need to address the issue of scarcity and burnout of available human resources. Hence, ensuring the well-being of health care workers is the need of the hour in this time of distress. WHO's Health Worker Safety Charter on World Patient Safety Day (September 17, 2020) appealed to the governments and those running local level health services to implement five planned actions to protect health workers better. ${ }^{18}$ It is needless to reiterate that the health care workers risking their lives at the forefront of the battle with this highly contagious virus should be provided with proper facilities and protective equipment without hindrance, so that they could work without undue concern for their own safety.

Nevertheless, the COVID-19 pandemic has caught us unprepared and has exposed the cracks within our healthcare system. It has also indirectly taught us that a long-term plan to facilitate the overall development of health care infrastructure should become our overall priority. We need to learn from this experience to strengthen the health care system, in order to avoid reaching the breaking point if such scenarios are encountered in the future.

\section{Conflict of Interest}

None declared.

\section{References}

1 Quinn SC, Kumar S. Health inequalities and infectious disease epidemics: a challenge for global health security. Biosecur Bioterror 2014;12(5):263-273

2 Lewnard JA, Lo NC. Scientific and ethical basis for social distancing interventions against COVID-19. Lancet Infect Dis 2020. Doi: 10.1016/S1473-3099(20)30190-0

3 Siow WJ, Liew MF, Shreshtha BR, Muchtar F, See KC. Managing COVID-19 in resource-limited settings: critical care considerations. Critical Care 2020. Doi: 10.1186/s13054-020-02890-X

4 Yang X, Yu Y, Xu J, et al. Clinical course and outcomes of critically ill patients with SARS-CoV-2 pneumonia in Wuhan, China: a single-centered, retrospective, observational study. Lancet Respir Med 2020;8(5):475-481

5 Brookings. Available at: https://www.brookings.edu/blog/ up-front/2020/03/24/is-indias-health-infrastructureequipped-to-handle-an-epidemic/. Accessed November 3, 2020

6 Gomersall CD, Tai DY, Loo S, et al. Expanding ICU facilities in an epidemic: recommendations based on experience from the SARS epidemic in Hong Kong and Singapore. Intensive Care Med 2006;32(7):1004-1013

7 Agrawal A, Gandhe M, Gandhe S, Agarwal N. Study of length of stay and average cost of treatment in medicine intensive care unit at tertiary care center. J Health Res Rev 2017;4:24-29

8 Turner HC, Hao NV, Yacoub S, et al. Achieving affordable critical care in low-income and middle-income countries. BMJ Glob Health 2019;4(3):e001675

9 Kroll RR, McKenzie ED, Boyd JG, et al; WEARable Information Technology for hospital INpatients (WEARIT-IN) study group. Use of wearable devices for post-discharge monitoring of ICU patients: a feasibility study. J Intensive Care 2017;5:64

10 Wahl B, Cossy-Gantner A, Germann S, Schwalbe NR. Artificial intelligence (AI) and global health: how can AI contribute to health in resource-poor settings? BMJ Glob Health 2018; 3(4): $\mathrm{e} 000798$ 
11 Shimabukuro DW, Barton CW, Feldman MD, Mataraso SJ, Das R. Effect of a machine learning-based severe sepsis prediction algorithm on patient survival and hospital length of stay: a randomised clinical trial. BMJ Open Respir Res 2017;4(1): e000234

12 Komorowski M, Celi LA, Badawi O, Gordon AC, Faisal AA. The Artificial Intelligence Clinician learns optimal treatment strategies for sepsis in intensive care. Nat Med 2018;24(11): $1716-1720$

$13 \mathrm{Ng} \mathrm{Z}$, Tay WC, Ho CHB. Awake prone positioning for non-intubated oxygen dependent COVID-19 pneumonia patients. Eur Resp J 2020. Doi: 10.1183/13993003.01198-2020

14 Branson RD, Blakeman TC, Robinson BR, Johannigman JA. Use of a single ventilator to support 4 patients: laboratory evaluation of a limited concept. Respir Care 2012;57(3):399-403
15 Neyman G, Irvin CB. A single ventilator for multiple simulated patients to meet disaster surge. Acad Emerg Med 2006;13(11):1246-1249

16 The Hindu. Available at: https://www.thehindu.com/news/ cities/chennai/cmc-goes-for-non-invasiveventilation-totreat-severe-cases/article32207843.ece. Accessed November 3, 2020

17 Whitson MR, Mo E, Nabi T, et al. Feasibility, utility, and safety of midodrine during recovery phase from septic shock. Chest 2016;149(6):1380-1383

18 World Health Organization. Available at: https://www.who. int/news/item/17-09-2020-keep-health-workers-safe-tokeep-patients-safe-who. Accessed November 3, 2020 